\title{
A Telecommunication Model to Teach Facilitators to Deliver Acceptance and Commitment Training
}

\author{
Carly Magnacca $^{1} \cdot$ Kendra Thomson $^{1,2}$ (1) Amanda Marcinkiewicz ${ }^{2,3} \cdot$ Sarah Davis $^{3} \cdot$ Lee Steel $^{2} \cdot$ Yona $_{\text {Lunsky }}{ }^{2}$. \\ Kenneth Fung ${ }^{4} \cdot$ Tricia Vause $^{3} \cdot$ Brianne Redquest $^{2}$
}

Accepted: 12 July 2021 / Published online: 16 August 2021

(C) Association for Behavior Analysis International 2021, corrected publication 2021

\begin{abstract}
Providing mediator training using a telecommunication format increases access to training by reducing geographical and financial barriers, while maintaining or increasing efficiency. Limited research has implemented this format to train facilitators in acceptance and commitment training (ACT), an empirically supported intervention. The aim of this research was to examine the efficacy of behavioural skills training via telecommunication for training novice facilitators to provide ACT to caregivers of individuals with neurodevelopmental disabilities. This two-part study involved concurrent multiple-baseline designs, each across 4 participants. Quantitative data on fidelity and confidence were collected at baseline, post-training, and at 1-month follow-up. The results from this study provide preliminary support for the use of behavioural skills training via telecommunication to train ACT facilitators. Increasing the number of competently trained facilitators will help build capacity to increase access to ACT across geographical regions.
\end{abstract}

Keywords Behavior skills training $\cdot$ Telecommunication $\cdot$ Acceptance and commitment training

Mediator training is essential within the field of behavior analysis to increase consumers' access to services (Parsons et al.,
2012). Behavioral skills training (BST) is an empirically supported, performance and competency-based training that

This research was completed as part of the first author's master's thesis at Brock University, supervised by the second author. We thank the participants and the Centre for Addiction and Mental Health.

\section{Highlights}

- Behavioral skills training via telecommunication was shown to be efficacious for teaching facilitators to implement three acceptance and commitment training experiential exercises as measured by treatment integrity checklists.

- Facilitators' performance maintained at 1-month follow-up, however generalization to untrained acceptance and commitment training experiential exercises did not occur.

- The results contribute to the growing literature regarding acceptance and commitment training in behavior analysis.

- Future research should explore the qualitative factors of acceptance and commitment training delivery as this training specifically focused on topography.

Kendra Thomson

kthomson@brocku.ca

1 Department of Applied Disability Studies, Brock University, St. Catharines, ON L2S 3A1, Canada
2 Azrieli Adult Neuordevelopmental Centre (Centre for Addiction and Mental Health), Toronto, ON, Canada

3 Department of Child and Youth Studies, Brock University, St. Catharines, ON, Canada

4 Department of Psychiatry, University of Toronto, Toronto, ON, Canada 
focuses on ensuring the trainee not only has a declarative knowledge of the skill (i.e., typically examined using written assessments), but is able to perform the skill accurately (Miles \& Wilder, 2009; Nigro-Bruzzi \& Sturmey, 2010; Parsons et al., 2012; Sarokoff \& Sturmey, 2004). BST has been demonstrated to effectively train mediators to implement a variety of interventions (e.g., Davis et al., 2019; Hassan et al., 2018; 2017; Hogan et al., 2015). Previous research suggests that in addition to BST being effective, it is also rated highly on acceptability measures by trainees (Davis et al., 2019; Gunby \& Rapp, 2014; Hassan et al., 2017, 2018; WardHorner \& Sturmey, 2012). When employing BST to train individuals that reside a considerable distance from the trainer or have other restrictions a telecommunication format can be leveraged for providing ongoing support.

Telecommunication models involve sharing information using a variety of technological platforms (e.g., video conferencing; World Health Organization, 2010), allowing for an increase in access to services by reducing geographical barriers. Training using a telecommunication model has been demonstrated to be as effective and efficient (e.g., Sump et al., 2018), and less expensive (e.g., Tomlinson et al., 2018) than in-person training. Telecommunication formats have been demonstrated to effectively train mediators to implement a variety of interventions, including teaching caregivers of children with neurodevelopmental disabilities (NDDs) to conduct functional analyses (Suess et al., 2016; Wacker, et al., 2013a), and training caregivers and staff to implement clinical behavioral interventions for children with autism spectrum disorder (ASD; Barkaia et al., 2017; Higgins et al., 2017; Wacker, Lee, Padilla Dalmau, Kopelman, Lindgren, Kuhle, Pelzel, Dyson, et al., 2013b). However, no research to our knowledge has explored the use of telecommunication to prepare individuals to facilitate acceptance and commitment training (ACT).

ACT is a third-wave behavioral therapy that focuses on increasing psychological flexibility by examining the impact of private events on overt behavior (Little et al., 2020). Further, it has been demonstrated to be efficacious for a variety of different populations, affecting a wide range of targets (e.g., anxiety, depression, stress, psychological flexibility; Gloster et al., 2020). Rooted in relational frame theory (RFT; Hayes, 2004; McEnteggart, 2018), ACT proposes that humans suffer in a unique manner due to arbitrarily applicable relational responding and the rapid development of human language (Hayes et al., 2006; McEnteggart, 2018). RFT posits that individuals relate stimuli based not only on formal similarity but also arbitrary cues (Hayes et al., 2013), and through these derived relations, stimulus function can be transformed. Transformation of stimulus function can be beneficial, but it is also how human suffering can occur (Fletcher \& Hayes, 2005), which may be addressed through ACT. Following an example in Tarbox et al. (2020), imagine your teenage niece, Alice, is kind and great with children. Alice is friends with
Ruth and Diane, and they all took a babysitting training workshop together. Although you have not directly met Ruth, you assume Ruth is kind and great with children because she is friends with Alice, who is both of those things. Without meeting Diane, you assume she must have similar qualities because she is friends with Ruth. However, when talking with another parent of a teenager, you find out that Diane and a couple of other teenagers were bullying younger children at school. Without any additional information, you infer the other bullies are Ruth and Alice, because they are all close friends. This results in transformation of stimulus function from Alice, Ruth, and Diane being thought of as kind to now being thought of as mean. There were changes in discriminative and reinforcement functions corresponding with the names Alice, Ruth, and Diane (Barnes-Holmes et al., 2004; Tarbox et al., 2020).

RFT involves the study of derived stimulus relations, where relational responding is considered a generalized operant (Healy et al., 2000). When forming relations, some are directly learned whereas others are derived (Hayes, 2004). It is through these derived relations that complex networks of verbal rules and associations are formed, usually based on contextual cues rather than physical attributes of the stimuli involved (Gross \& Fox, 2009). The interconnection between ACT and RFT has been empirically researched, with some considering them to have co-evolved (McEnteggart, 2018). The growing popularity and need to increase the accessibility of ACT led to the development of the hexaflex model (Foody et al., 2013). The hexaflex model outlines six core therapeutic processes (i.e., present moment awareness, defusion, acceptance, self-as-context, values, and committed action) that lead to increased psychological flexibility (Hayes et al., 2006). All of the core processes are interconnected and lead to psychological flexibility and socially significant overt behavior changes (Hayes et al., 2006; Little et al., 2020). The hexaflex model has many benefits but has also made the intervention's foundation in RFT less easily apparent (McEnteggart, 2018). However, the link between ACT and RFT is advantageous to the conceptual development of ACT practice.

Through the application of behavioral principles including RFT, ACT addresses current private events through the core processes within the "hexaflex," to in turn, regulate overt behaviors (Hayes et al., 1999). Each core process is designed to ameliorate a psychological process that is thought to influence the emergence of psychological inflexibility (Hayes et al., 2006). The core therapeutic processes for ACT are interdependent, affecting psychological flexibility through the entire hexaflex (Harris, 2009), which can be explained behaviorally.

Present moment awareness involves attending to stimuli in the present moment, rather than attending to private events regarding the past and future (i.e., wandering behavior; Little et al., 2020). It can also involve increasing attending to one's private events through tacting (e.g., I'm having the thought that. . .."; Little et al., 2020). Engaging in present moment 
awareness allows for actions to be shaped by current contingencies and adaptive to the moment (Hoffmann et al., 2016). Further, by attending to one's private events, tacting "wandering" behavior can act as a discriminative stimulus to redirect one's attention to the present moment (Tarbox et al., 2020). For example, if in a social situation an individual attends to a past experience when they felt that they were too shy, they may not attend to the current stimuli and miss opportunities for social reinforcement. However, if that individual were to tact their "wandering" behavior, this may function as a discriminative stimulus for redirecting attention to the present social situation. Present moment awareness addresses dominance of the conceptualized past and feared future, which includes private events focused on past or future events or states about one's self (e.g., "what if" thoughts, or "if only" thoughts; Harris, 2009).

Private events are sometimes incorrectly interpreted as if they are concrete or physical stimuli in the external environment (Hoffmann et al., 2016). For example, the behavior is relating to one's experience in a mentalistic way, resulting in cognitive fusion (Tarbox et al., 2020). Cognitive fusion may occur without awareness, where verbal rules exert more control over behavior than contingencies in the external environment (Hoffmann et al., 2016; Snyder et al., 2011). For example, cognitive fusion may result in private event being constructed as a rule, preventing an individual from engaging in value-directed behavior. The process of defusion involves deliteralizing language, specifically language involving unhelpful rules (Harris, 2009). Defusion exercises typically involve different strategies to help recognize unhelpful rules and to instead identify private events as just words that do not dictate behavior through the use of word repetition or other exercises that may have humorous functions (Tarbox et al., 2020) Attending to one's private events is necessary in order to implement defusion (Hoffmann et al., 2016).

Experiential avoidance involves the attempt to alter the frequency or form of aversive overt or covert events, including thoughts, feelings, or situations (Hayes et al., 1996; Tarbox et al., 2020). Although avoiding private events may be negatively reinforcing in the short term, it may have undesirable consequences, such as reducing an individual's engagement in value-directed behaviors, and potentially affecting a person's mental health in the long term (Hoffmann et al., 2016). Acceptance involves engaging in approach behavior (e.g., acknowledging and engaging with private events and bodily sensations, rather than avoiding or escaping; Harris, 2009; Little et al., 2020; Tarbox et al., 2020).

The conceptual self involves how individuals view themselves (Hayes et al., 2006), which can influence overt behavior (Hoffmann et al., 2016). For example, if an individual views themself as "too shy" this may become a rule, and therefore, the individual may not engage in value-directed behaviors that involve socializing to avoid negative feelings that accompany being "too shy." The conceptual self can include negative self-talk, such as "I'm not good enough" or "I'm not smart enough." Self-as-context involves flexible perspective taking, promoting the perception that an individual is not the content in one's thoughts, but rather the context. The implementation of flexible perspective taking can deconstruct rules regarding oneself (e.g., I am too shy) to in turn alter motivation and increase engagement in value-driven behaviors (Hoffmann et al., 2016). Although self-as-context may sound similar to and hard to distinguish from defusion, the two differ in that the former focuses on flexible rules about the self, and the latter targets flexible rules regarding the outside world (Tarbox et al., 2020).

Values clarification targets a lack of direction in life and focuses on identifying how one wants to behave that is in accordance with what they value (Harris, 2009). Values are thought to be similar to motivating operations; they can derive functional properties through language (Hoffmann et al., 2016). Therefore, even without previous contact, values can influence the reinforcing effectiveness of stimuli (Hoffmann et al., 2016). By identifying values, an establishing effect may occur, leading to engagement in values-consistent behavior (Hoffmann et al., 2016).

Committed action targets inaction and emphasizes engaging in value-guided actions, even if it brings up challenging private events (Hayes et al., 2006). This process is the most aligned with traditional behavior therapy as it can involve the implementation of behavioral principles (e.g., defining the target behavior, self-management strategies, and the manipulation of antecedents and consequences to increase the probability of the actions occurring; Hayes et al., 2006). Through targeting the other five core processes (i.e., values, present moment awareness, defusion, self-as-context, acceptance), the goal is to increase one's engagement in value-directed behaviors (Tarbox et al., 2020).

$\mathrm{ACT}$ is a growing intervention across many fields, including nonbehavior analytic applications. To distinguish the psychotherapeutic application of ACT from the behavior analytic application, the terminology "acceptance and commitment training" rather than "acceptance and commitment therapy" has been encouraged (Szabo, 2019; Tarbox et al., 2020). When behavior analysts are practicing ACT, there are a few considerations. First, it is important that ACT meets the same standards of practice relevant for other interventions (Tarbox et al., 2020). Tarbox et al. (2020) outlined ACT's linkages to behavioral principles, including the seven dimensions of applied behavior analysis (Baer et al., 1968), as well as items included on the Behavior Analytic Certification Board Task List, $5^{\text {th }}$ edition (e.g., functional assessment, rule governed behavior, motivating operations; Behavior Analyst Certification Board, 2017). It is also important to consider scope of competence in addition to scope of practice. In a survey completed by 303 American Board Bertified 
Behavior Analysts (BCBAs), the majority of respondents agreed that ACT is within the scope of applied behavior analysis but not within their scope of competence (Enoch \& Nicholson, 2020). Therefore, just like other behavior analytic interventions, it is important to seek specialized training to ensure the delivery of ACT in a conceptually systematic manner (Tarbox et al., 2020).

ACT has been demonstrated to improve the well-being of a diverse range of populations, including caregivers of individuals with neurodevelopmental disabilities (e.g., Brown et al., 2015; Hahs et al., 2018; Lunsky et al., 2018). Caregivers of individuals with NDDs may experience higher levels of stress and are at greater risk for experiencing mental health concerns in comparison to caregivers of children without disabilities (Dykens et al., 2014; Estes et al., 2009; Miodrag \& Hodapp, 2010; Taylor \& Warren, 2012). However, little attention has been paid to interventions that directly target parent stress, with most interventions training caregivers to teach skills to their child (Lunsky et al., 2018). The purpose of these ACT workshops is to teach caregivers to implement ACT in their own life. The ACT perspective emphasizes accepting the unchangeable (Losada et al., 2015), which may fit the needs of caregivers experiencing high levels of stress, especially those of children with disabilities (Lunsky et al., 2018). Of the limited research that has addressed caregiver-focused interventions, ACT has been demonstrated to significantly improve psychological flexibility (Blackledge \& Hayes, 2006; Brown et al., 2015; Fung et al., 2018; Gould et al., 2018; Hahs et al., 2018; Joekar et al., 2016; Poddar et al., 2015; Whittingham et al., 2016).

The administration of ACT for caregivers of children with NDDs is most frequently conducted in a group format with experts facilitating didactic and experiential components, with little attention placed on the facilitators' performance and competency of ACT activities (Magnacca et al., 2021). Facilitators' fidelity of ACT delivery is underreported in the ACT-caregiver literature (Magnacca et al., 2021), and we know even less about the fidelity of facilitators just learning to deliver ACT. Although previous research has demonstrated significant improvements in caregivers' mental health and psychological flexibility postintervention, there tends to be a decrease in improvements at follow-up for the limited studies that have included follow-up assessments, suggesting limited programming for maintenance (e.g., Blackledge \& Hayes, 2006). Therefore, additional strategies may be needed to promote maintenance of ACT benefits over time. Poddar et al. (2015) suggested that the addition of behavioral training methods implemented by facilitators when teaching ACT to caregivers may help combat the reduction of treatment outcomes displayed over time. Gould et al. (2018) incorporated instructions, role-playing, and practice when providing ACT to caregivers of children with ASD in an individual format. Caregivers demonstrated improvements in psychological flexibility and overt value-directed behaviors, with the largest effects demonstrated at the 6-month follow-up evaluation. These results suggest that using performance and competency-based training in an individual format may combat the decline in effects of ACT over time (e.g., Poddar et al., 2015). Given that ACT for caregivers of children with NDDs is often conducted in a group workshop setting, incorporating BST may not be feasible in this format without increasing the workshop length. Caregivers of children with NDDs often have demanding schedules and increased workshop length may not be feasible. With previous research demonstrating that fidelity (e.g., Fryling et al., 2012) influences treatment outcomes, it is important to consider the fidelity with which facilitators provide ACT to others.

In addition, therapeutic alliance has also been demonstrated to influence the effectiveness of interventions (Derksen et al., 2013; Keeley et al., 2011; Kirby et al., 2017; Weiss et al., 2017). With the goal of improving therapeutic alliance between ACT participants and facilitators, Lunsky et al. (2018) and Fung et al. (2018) included caregivers of children with disabilities as ACT cofacilitators, with the additional support of a psychiatrist. Including caregivers as cofacilitators has been encouraged in the literature because it increases relevancy of the material, which may increase treatment acceptability for other caregivers participating in ACT sessions (Dykens et al., 2014; Lunsky et al., 2018). Further, including caregivers as cofacilitators may increase the acceptability of the intervention as a result of caregiver facilitators' increased compassion. In behavioral terms, compassion has been described as being rooted in RFT (i.e., deictic frames; Barnes-Holmes et al., 2013) and involving perspective taking (Taylor et al., 2019). For example, Taylor et al. (2019) outlines that perspective taking involves a series of interpersonal relations including the I-you, here-there, and now-then deictic relations. In particular, including a caregiver facilitator with lived experience who can relate to the workshop participants may result in increased compassion.

Although incorporating caregivers as cofacilitators for ACT workshops has been demonstrated to be beneficial, the challenge is to build capacity to scale up and implement ACT workshops more broadly to benefit more caregivers, while capitalizing on training resources available. To increase the number of facilitators trained to deliver ACT, Fung et al. (2019), developed the Acceptance and Commitment Training (ACT) Manual for Parents with Children with Disabilities, outlining how to facilitate ACT workshops for caregivers of children with disabilities. The training occurs in-person across 2 weekends in a group setting, with caregiver-clinician facilitator dyads formed based on geographical location. Little is known about the fidelity of facilitators trained with this format and whether additional training may be warranted. 
There is a dearth of research on ACT facilitator training in general, with little research incorporating training via telecommunication. To our knowledge, direct measures (i.e., measuring observable and operationally defined behaviors) to examine facilitators' delivery of ACT experiential exercises following training (Plumb \& Vilardaga, 2010) are also lacking. Further, ACT fidelity measures are often intended for the psychotherapeutic delivery of ACT rather than a behavior analytic application or focus on ACT for a different population (e.g., individuals with obsessive compulsive disorder; Twohig et al., 2010). The addition of BST, in particular the rehearsal and feedback components, via telecommunication may be a potential solution to increase the number of people that can facilitate ACT and improve facilitator fidelity and confidence. Implementing training using telecommunication may be especially beneficial for increasing convenience and feasibility for caregiver and clinician trainees that may be experiencing high levels of stress and balancing multiple responsibilities. Although BST can be implemented in a group format, there are additional challenges that should be considered, in particular when providing the training online. Not only would conducting group training likely increase the length of the training for the participants, but the quality of the training may be negatively affected due to the increased bandwidth required and lack of access to high-speed internet in rural or remote areas. Further evaluation is needed to determine how to effectively and efficiently train ACT facilitators.

The purpose of this study was to evaluate the use of BST via telecommunication for providing additional training to caregiver and clinician facilitators who had previously taken part in manualized, group-based ACT facilitation training (Fung et al., 2019), which was conducted separately prior to this research. The BST sessions via telecommunication focused on teaching participants to facilitate three experiential exercises that they were planning to later deliver in workshops to caregivers of individuals with NDDs as evaluated in Lunsky et al. (2018) and Fung et al. (2018). This study extends the previous literature by evaluating the efficacy of BST via telecommunication for increasing ACT facilitator fidelity measured directly through observable behaviors.

\section{General Method}

\section{Participants, Setting, and Materials}

We recruited a total of eight participants (four caregivers, two clinicians, and two participants who identified as both a clinician and caregiver) that previously received some iteration of the manualized, group-based ACT facilitation training (Fung et al., 2019). Selecting participants that had already received this manualized, group-based ACT facilitation training allowed the current training to focus on the integrity of facilitation of the ACT experiential exercises rather than teaching the foundations of ACT or participating in the experiential activities. Further, recruiting from a group of individuals that had already expressed interest in becoming ACT facilitators assisted with the success of the recruitment process. The manualized, group-based ACT facilitation training was conducted separately from this study.

Inclusion criteria consisted of (1) being either a clinician or primary caregiver of an individual with an NDD of any age; (2) ability to speak, read, write, and comprehend the English language; (3) having access to the internet using an appropriate technological device; and (4) completion of a manualized, group-based ACT facilitation training. All participants had committed to serving as cofacilitators of future ACT workshops in their geographical regions but had not conducted any workshops prior to or during this study. There were no additional exclusionary criteria. All participants were females between 46 and 66 years of age. Additional demographic data are included in Table 1.

All training sessions were conducted via telecommunication using an encrypted, videoconferencing software program $\left(\right.$ Lifesize $^{\mathrm{TM}}$ ), that allows video and audio recording of sessions and is compliant with the Personal Information Protection and Electronic Document Act (Canada) and the Health Insurance Portability and Accountability Act (U.S.). Participants accessed Lifesize ${ }^{\mathrm{TM}}$ through their preferred or accessible device, including smartphones and laptops that connected to wi-fi and had a built-in camera and audio capabilities. The researcher (i.e., trainer) connected to Lifesize ${ }^{\mathrm{TM}}$ using a computer located within a confidential environment on the university campus. Participants used Fung et al.'s (2019) manual, which was provided to them during the manualized, group-based ACT facilitation training throughout the study. Additional training resources (i.e., a table summarizing the core processes of $\mathrm{ACT}$ ) were provided to the participant online using a file hosting service (i.e., Dropbox ${ }^{\mathrm{TM}}$ ) or via email.

\section{Experimental Design}

A concurrent multiple baseline design across participants was used to evaluate the efficacy of BST via telecommunication for increasing facilitator fidelity when leading a selection of common ACT experiential exercises.

\section{Measures and Interobserver Agreement}

\section{ACT Facilitation Fidelity}

Participants' ACT facilitation fidelity was measured using a treatment integrity checklist for three ACT experiential exercises from the Fung et al. (2019) manual (i.e., hexaflex, matrix, and le'go). Of the three experiential exercises included, 
Table 1 Demographic information

\begin{tabular}{lllll}
\hline & Geographical region & Facilitator role & Education & Ethnicity \\
\hline Participant 1 & Nova Scotia & Caregiver & Bachelor's degree & White \\
Participant 2 & Newfoundland & Clinician & Master's degree & White \\
Participant 3 & Nova Scotia & Caregiver & Bachelor's degree & White \\
Participant 4 & Quebec & Caregiver/Clinician & Bachelor's degree & White, Asian \\
Participant 5 & Ontario & Caregiver & Master's degree & White \\
Participant 6 & Nova Scotia & Clinician & Master's degree & White \\
Participant 7 & Alberta & Caregiver & Some college credit, no degree & White \\
Participant 8 & Newfoundland & Caregiver/Clinician & Doctorate degree & White \\
\hline
\end{tabular}

one exercise was considered the untrained skill to demonstrate experimental control and assess for generalization. The treatment integrity task analysis was developed by the researcher team based on general guidelines outlined by Plumb and Vilardaga (2010), along with input from ACT experts (a psychiatrist and caregiver ACT facilitator with extensive experience delivering manualized ACT workshop; Fung et al., 2019). The treatment integrity checklist outlined essential steps (i.e., explaining the relevant processes, leading the exercise, debriefing, and answering questions) consistent among the ACT experiential exercises (Fung et al., 2019), and was used to calculate the participants' percent correct fidelity implementing the ACT experiential exercises by dividing the number of steps implemented correctly by the total number of steps and multiplied by 100 . The trainer collected primary fidelity data in-vivo (while observing the participant online) and a trained research assistant collected secondary fidelity data using video recordings of the online sessions post-hoc. Item-by-item interobserver agreement (IOA) was calculated from a random sample (using a random number generator) of $34 \%$ of sessions across all phases and averaged 93\% (range: $75 \%-100 \%$ ) for Study 1. For Study 2, IOA was calculated following the same protocol for a random sample (using a random number generator) of $33 \%$ of sessions across all phases and averaged 96\% (range: $75 \%-100 \%$ ).

Experiential exercises Operational definitions for each of the experiential exercises are included in Appendix 1.

Matrix In this activity the facilitator presents an interactive tool and explains the difference between internal and external stimuli and behaviors (Axis 1), that either align or deviate from one's values (Axis 2). Facilitating the activity involves explaining how the different core processes relate to these axes and psychological flexibility. Facilitators define values, committed action, experiential avoidance, and avoidant behaviors, while recording personal examples of each provided by the workshop recipients. The facilitators then explain the short-term and long-term benefits of engaging in behaviors recorded on all four quadrants of the matrix. In particular, when engaging in behaviors identified under the experiential avoidance and avoidant behavior subsets, these behaviors are often negatively reinforcing in the short term, and behaviors under the values and committed action are reinforcing in the long term, such as leading to the achievement of long-term goals. The facilitator then debriefs by explaining the importance of noticing these behaviors, (i.e., attending to and tacting one's private and overt behaviors). Overall, the exercise outlines the importance of present-moment awareness to tact one's private and overt behaviors, and how they relate to values. Facilitating this activity involves explaining the relevant processes, collecting and recording participant responses, debriefing, and answering questions.

Describing the hexaflex In this activity, facilitators describe the psychological flexible processes (present moment awareness, defusion, acceptance, self-as-context, values, and committed action) and inflexible processes (dominance of the conceptualized past and feared future, cognitive fusion, experiential avoidance, attachment to the conceptualized self, lack of values clarity, and inaction, impulsivity, or avoidance) of the hexaflex, including a small experiential component involving facilitating the corresponding hand gesture for each process as a visual representation. As part of the manualized, groupbased ACT workshop by Fung et al. (2019), the facilitators provide a presentation about the ACT processes involving the incorporation of real-life examples. During the presentation, it is outlined that the workshop participants will first learn about the ACT processes in a more didactic format as an overview, and will then experience the processes as the workshop proceeds though experiential exercises. While debriefing experiential exercises, the workshop participants are reminded of the hexaflex and ACT processes, and the facilitators are encouraged to incorporate relevant real-life examples (e.g., caregiving examples).

Le'go (untrained skill) The facilitators lead the participants through a self-as-context and present moment awareness exercise, involving reflecting back on three memories from three points in time (last summer, teenage years, and childhood). 
Participants are then asked to represent each of these memories using Lego pieces on a paper plate while observing one's private events and responding to one's own responding (Dymond \& Barnes, 1997). Facilitators then debrief by explaining the observer self and the consequences of rigidly defining one's sense of self. Further, facilitators remind participants about how behavior can be under the control of rules about oneself (i.e., attachment to the conceptualized self) rather than contingencies in the environment. The facilitator follows a script, debriefs, and answers questions.

\section{Confidence Ratings}

Participants rated their perceived confidence in facilitating ACT with others using a 5-point Likert scale $(1=$ "completely disagree," $5=$ "completely agree"). The rating form consisted of 15 questions that were based on the Teaching Confidence Scale (Hoy, 2000). The measure was administered before and after BST via telecommunication, and at 1-month follow-up. Participants completed this measure using Qualtrics ${ }^{\circledR}$, an online survey platform.

\section{Social Validity}

To measure the acceptability of the procedure, participants rated the acceptability of the BST and telecommunication format, on 14-item social validity measure $(1=$ "completely disagree," $5=$ "completely agree"). The measure was modified from the Treatment Acceptability Rating Form-Revised (TARF-R; Reimers et al., 1991) and the social validity measure included in Hassan et al. (2018). We also included an optional open-ended section for participants to share any additional comments. Participants completed this measure anonymously online via Qualtrics ${ }^{\circledR}$ after the 1-month follow-up assessment to reduce social desirability bias while still participating in the study because the researcher was known to the participants.

\section{Researcher Procedural Integrity}

A trained research assistant collected procedural integrity data on the researcher's behavior using video recordings for a randomly selected $34 \%$ of sessions using a checklist of accurate implementation of BST during the training sessions with participants (see Appendix 2). Procedural integrity was $100 \%$ for Study 1 and Study 2. Item-by-item IOA was calculated by the trainer self-recording in-vivo for the same $34 \%$ of online sessions across all phases for Study 1 and Study 2, which was $100 \%$.

\section{General Procedure}

The study consisted of seven phases: preparation phase, Phase 1: Baseline, Phase 2: BST via Telecommunication, Phase 3: Post-BST via Telecommunication, Phase 4: BST via Telecommunication for the Untrained Skill, Phase 5: PostBST via Telecommunication for the Untrained Skill, and Phase 6: 1-Month Follow-Up via Telecommunication.

\section{Preparation Phase}

The research team reviewed the ACT manual by Fung et al. (2019) and selected a variety of potential experiential exercises that would be applicable to the online facilitation format. These experiential exercises were then discussed with ACT experts, a psychiatrist and caregiver ACT-facilitator with extensive experience (facilitated $>10$ workshops) to select experiential exercises involving different facilitation skills (i.e., following a script, evoking participation from workshop participants, and didactic format including explaining the core processes), yet were agreed to be approximately equivalent in facilitation difficulty levels by the team. Further, the researcher and the expert caregiver facilitator compiled a list of commonly asked questions by ACT workshop recipients for each exercise. The trainer asked the participants these questions in a randomized order (using a random number generator) in training sessions when role-playing an ACT workshop recipient across all phases. The researchers and ACT expert then created video models for the three experiential exercises with the ACT caregiver expert facilitating the activities and the researchers role-playing participants. The videos included all components outlined in the treatment integrity checklists.

\section{Phase 1: Baseline}

Participants were first asked to complete a demographic survey and confidence rating form. Next, ACT facilitation fidelity data were collected by having each participant meet with the researcher via Lifesize ${ }^{\mathrm{TM}}$ individually to facilitate all three of the selected ACT experiential exercises from the manual (i.e., hexaflex, matrix, le'go; Fung et al., 2019). The participants were provided with the manual, the page number of the relevant experiential exercises, and $2 \mathrm{~min}$ to review the detailed instructions for facilitating the exercise. Participants were provided with 2 min to allow time to review the activity in general, but not enough time to further practice the activity. Therefore, baseline was assessing their facilitation skills following the manualized, group-based ACT facilitation training rather than their self-taught facilitation skills. The researcher role-played an ACT workshop recipient and followed a script including frequently asked questions (e.g., "What is the difference between ACT and cognitive behavioral therapy?"; 
"How do values differ from goals?"; "How does this exercise relate to my daily life?") and responses that were gathered from experienced ACT facilitators to respond consistently across participants (see Appendix 1 for information on how participant's responses were scored). Baseline sessions were approximately $1 \mathrm{hr}$ in length and no feedback was provided to participants.

\section{Phase 2: BST via Telecommunication}

In this phase, participants received BST via telecommunication for two of the target ACT experiential exercises (i.e., hexaflex and matrix). Participants completed Phases 2 and 3 for the first experiential exercise before receiving any training for the second experiential exercise. The specific experiential exercise that was trained first was counterbalanced across participants. The BST via telecommunication format included an initial training session (90 min in length), which involved the trainer providing instructions and a video model and providing the participant with an opportunity to rehearse facilitating the experiential exercise twice with the researcher providing contingent feedback. If the participant did not meet the mastery criterion in the initial training session (facilitating the experiential exercise twice at $100 \%$ fidelity), subsequent training sessions (20 min in length) were conducted, which involved the trainer answering any of the participant's questions, and two opportunities for the participant to rehearse with feedback. To reduce the potential of fatigue influencing performance, participants facilitated the experiential exercise a maximum of twice per session. The number of subsequent training sessions varied per participant and per skill (ranging from zero to two additional training sessions) as these sessions were conducted until the participant met the mastery criteria.

Instructions The trainer provided a brief didactic presentation, including reviewing the experiential exercise script in the manual. The trainer then reviewed the materials involved in the exercise and provided a brief rationale for the exercise. Lastly, the trainer answered any questions that were brought up during Phase 1 (baseline), or any new questions the participant had.

Modeling The trainer provided an instruction to the participant to watch a video model of the specific ACT experiential exercise they would then be asked to facilitate. The participant was provided a link to the video via Dropbox ${ }^{\mathrm{TM}}$. The participant remained on Lifesize ${ }^{\mathrm{TM}}$ while viewing the video. The participants were told that they could pause, rewatch, take notes, and ask the trainer any questions throughout the video (approximately $20 \mathrm{~min}$ in length).

Rehearsal and feedback Participants were provided with two opportunities to practice facilitating the specific ACT experiential exercise within each training session, with the trainer providing contingent feedback immediately following facilitation. The trainer provided social descriptive praise, and corrective feedback if the participant scored below $100 \%$ on the treatment integrity checklist. Sessions, which included a maximum of two attempts of the exercise to reduce fatigue from influencing performance, were conducted until the participant met the mastery or coaching criteria.

In-vivo coaching If the participant did not reach the mastery criterion after five facilitation sessions (10 attempts), in the BST via telecommunication phase, the trainer added coaching (i.e., live, in-vivo feedback), such as providing corrective feedback while the participant was facilitating rather than providing the feedback following facilitation of the activity.

\section{Phase 3: Post-BST via Telecommunication}

Following training participants were asked to facilitate the ACT experiential exercise three times total across two sessions. At least 1 day following the completion of Phase 2, the researchers conducted three trials in posttraining phases because it allowed for an assessment of trend. As in baseline, the participant facilitated the activity with the trainer roleplaying an ACT-workshop recipient. The trainer's responses were scripted based on commonly asked questions/responses described above and held constant across participants. After this phase, the participant then completed Phase 2 for the second ACT experiential exercise. During Phase 3 for the second experiential exercise, the untrained skill was probed under baseline conditions. If the participants' facilitation fidelity score was below $80 \%$ for the untrained skill, the participant proceeded to Phase 4.

\section{Phase 4: BST via Telecommunication for the Untrained Skill}

If the participants' facilitation fidelity score for the untrained skill was below $80 \%$ when probed under baseline conditions in Phase 3, training was provided for the untrained skill. This training was conducted following completion of Phase 3 . The training followed the same steps outlined in Phase 2.

\section{Phase 5: Post-BST via Telecommunication for the Untrained Skill}

If the participant required training for the untrained skill, the participants completed Phase 5 following completion of Phase 4, with the trainer role-playing at ACT-workshop recipient using scripted responses. Phase 5 followed the same steps outlined in Phase 3, however was conducted at a later point in time than the other skills (i.e., following Phase 4). As in Phase 3, the participants were asked to facilitate the newly trained experiential exercise three times total across two 
sessions. Next, the participants were also asked to complete the confidence rating form online within a week of the training.

\section{Phase 6: 1-Month Follow-Up via Telecommunication}

One month following completion of Phases 3 and 5 for the specific experiential exercise, the participant facilitated the ACT experiential exercise with the trainer role-playing an ACT-workshop recipient and completed the confidence measure again. If the participant's facilitation fidelity was below $80 \%$ fidelity, the researcher had planned to offer a booster training session, which was not required for any of the participants. Further, participants completed the social validity measure online within a week of the follow-up assessment.

\section{Study 1}

\section{Participants, Materials, and Setting}

We recruited two caregivers, one clinician, and one participant who identified as both a caregiver and clinician. Participants had completed an in-person, manualized group-based ACT facilitation training (Fung et al., 2019). The training involved participants first taking part in an in-person ACT workshop to experience the manualized ACT intervention (Weekend 1; 10 hr). Next, the participants attended another in-person workshop focusing on how to facilitate the manualized ACT intervention (Weekend 2; $12 \mathrm{hr}$ ). Experienced facilitators further explained the ACT model and demonstrated some of the experiential exercises included in the manual (Fung et al., 2019). Following the completion of the in-person group-based, manualized ACT facilitation training, participants were invited to practice facilitating the exercises included in the ACT manual on their own, but no formal contingency was in place for doing so. None of the exercises that were demonstrated during this training were selected for the current study to control for prior learning because the facilitators had some opportunities to practice (at times with feedback).

\section{Procedure}

The procedure for Study 1 is the same as the general procedure. For Study 1, Phase 1 occurred 6 weeks following participants' completion of the in-person manualized, groupbased ACT facilitation training (Fung et al., 2019). Baseline data were collected within 1 week, and Phases 2 through 5 occurred over 6 weeks. A minimum of one trial and maximum of five trials were conducted weekly. On occasion, two trials were conducted on the same day with a minimum of $5 \mathrm{hr}$ between trials. With exception of the follow-up, all data were collected within 6 weeks.

\section{Study 1 Results}

Figure 1 depicts all four participants' facilitation fidelity of the ACT experiential exercises in a multiple baseline

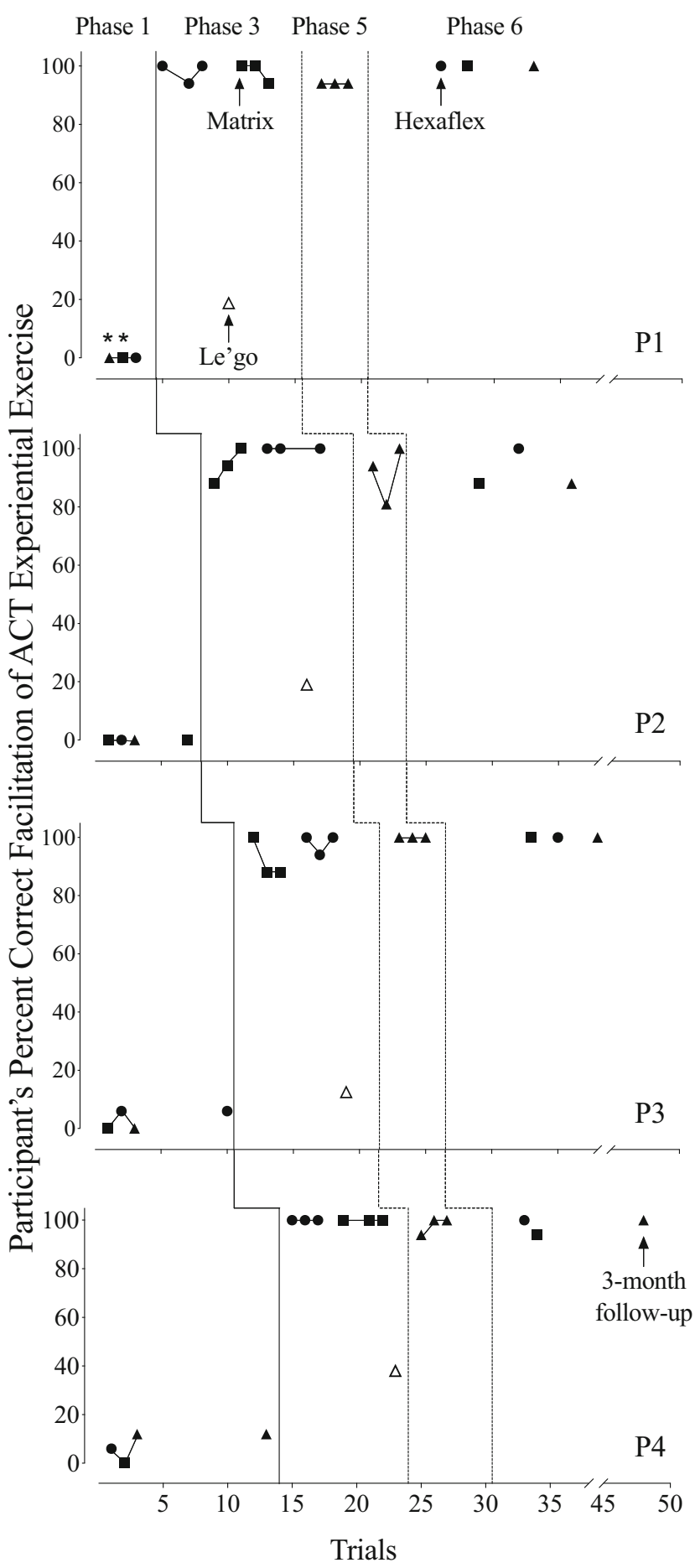

Fig. 1 Participants' Facilitation Fidelity of ACT Exercises. Note. The asterisk denotes that the participant did not facilitate the correct experiential exercise. A trial included one attempt of facilitating an experiential exercise. The data path is broken when trials were conducted more than a week apart 
design. Figure 1 includes facilitation fidelity data from baseline, posttraining, and at the 1-month follow-up (i.e., Phase 1, Phase 3, Phase 5, and Phase 6). Overall, the participants demonstrated stable and low fidelity scores in the baseline phase $(M=3.00 \%, S D$ $=4.56$, range: $0-12 \%)$. Following the implementation of BST via telecommunication, significant level change was demonstrated $(M=97.5 \%, S D=4.30$, range: $88 \%-100 \%$ ). The average mean shift from baseline to Phase 3 was $94.88 \%$ across participants. In Phase 3, facilitation fidelity of the untrained skill (le'go) increased slightly but remained low and below the predetermined performance criterion $(M=22.06 \%, S D$ $=11.04$, range: $12.5 \%-38 \%$ ). Therefore, training was provided to all participants for the untrained skill. Fidelity scores were high and stable following BST for the untrained skill $(M=95.92 \%, S D=5.57$, range: $81 \%-100 \%)$. At the 1-month follow-up, fidelity for Participants 1,2, and 3 remained high and stable ( $M$ $=97.00 \%, S D=5.10$, range: $88 \%-100 \%$ ). Due to illness, Participant 4 completed a 3-month follow-up for the untrained skill at which point her fidelity remained high and stable $(M=100 \%)$.

Results of facilitators' performance during training (Phase 2 and Phase 4) of the intervention are displayed in Table 2. Overall, the implementation of BST led to an immediate increase in facilitation fidelity, with an average mean shift of $86.34 \%$ in Phase 2 and $94.79 \%$ in Phase 4 . The average amount of time required to complete the training for the first skill (i.e., hexaflex for Participant 1 and 4, matrix for Participant 2 and 3) was approximately $1.83 \mathrm{hr}$. This time decreased to $1.67 \mathrm{hr}$ for the second skill (i.e., matrix for Participant 1 and 4, hexaflex for Participant 2 and 3), and remained approximately the same at 1.62 $\mathrm{hr}$ for the third skill (i.e., le'go).

For Participant 1, the participant reached the mastery criterion in three sessions (five trials) for this skill, and therefore, no coaching was required. Likewise, for Skill 2 (matrix), the participant reached the mastery criterion within two sessions (four trials). For Skill 3 (le'go), Participant 1 reached the mastery criterion in two sessions (three trials).

Table 2 Number of training trials required to reach the mastery criterion

Number of trials to reach mastery criterion

\begin{tabular}{llll} 
& Skill 1 & Skill 2 & Skill 3 (Untrained Skill) \\
\hline Participant 1 & 5 & 4 & 3 \\
Participant 2 & 3 & 3 & 2 \\
Participant 3 & 5 & 3 & 3 \\
Participant 4 & 3 & 2 & 3 \\
\hline
\end{tabular}

For Participant 2, the mastery criterion was achieved in two sessions (three trials) for the first two skills (matrix and hexaflex), and one session (two trials) for the le'go exercise. Therefore, coaching was not required within the BST phases (Phase 2 and 4).

Participant 3 reached the mastery criterion in three sessions (five trials), therefore, coaching was not required. For Skill 2 (hexaflex) and 3 (le'go), the mastery criterion was reached within two sessions (three trials).

Participant 4 met the mastery criterion in two sessions (three trials) for Skill 1 (hexaflex) and Skill 3 (le'go). For Skill 2 (matrix), Participant 4 reached the mastery criterion in one session (two trials). Coaching was not required for Participant 4.

Participants ranked their confidence facilitating ACT experiential exercises as high following completion of the manualized, group-based ACT facilitation training ( $M=$ 4.18; using the 5-point Likert scale), which was not consistent with their facilitation fidelity scores at baseline (Phase 1). Confidence scores remained high after receiving BST via telecommunication $(M=4.53)$, and highest at the 1-month follow-up $(M=4.97)$.

In general, participants rated the purpose of the study, training outcomes, BST, and the telecommunication format as highly acceptable. In particular, participants rated the purpose of the study, the training outcomes, and the telecommunication format as a mean of "5" and BST a " 4.75 " on the 5-point Likert scale $(1=$ "strongly disagree," $5=$ "strongly agree"). In the optional, open-ended section, participants included positive remarks about the BST, including Participant 3 who stated, "This absolutely helped me understand and learn how facilitate the ACT program."

\section{Study 2}

\section{Participants, Materials, Setting}

For Study 2, we recruited four participants (two caregivers, one clinician, and one participant who identified as both a clinician and caregiver) that did not participate in Study 1. Participants received the same in-person manualized, group-based ACT facilitation training (Fung et al., 2019) as the participants in Study 1, but also received monthly, virtual follow-up training sessions. The virtual follow-up training sessions involved 2-hr sessions where the same experienced facilitators that conducted the in-person training reviewed specific processes and ACT exercises each month. Following each monthly virtual session, participants were asked to gather in their assigned smaller groups (approximately groups of four) and video record one group member 
facilitating the exercise with the other group members role-playing as workshop participants. Each group was to post their video recording to an online platform where other groups and the facilitators provided feedback. There were no consequences if groups did not post a video. Further, because only one group member facilitated, some group members did not facilitate an exercise throughout this training process.

\section{Study 2 Procedure}

Given the additional training provided to Study 2 participants, a second baseline assessment was conducted within 2 weeks of the final virtual monthly, follow-up training session. Besides the addition of the second baseline assessment, the procedure for Study 2 was the same as outlined in the general procedure. The first baseline assessment occurred 6 weeks following participants' completion of the in-person manualized, groupbased ACT facilitation training. The second baseline assessment occurred within 2 weeks of participants' completion of virtual, monthly follow-up sessions. Phases 2 through 5 were conducted over a longer length of time compared to Study 1 to accommodate participants' changing schedules and responsibilities throughout the COVID-19 pandemic (i.e., 6 months instead of 6 weeks). A maximum of five trials were conducted weekly. Occasionally, two trials were conducted on the same day with a minimum of $5 \mathrm{hr}$ between trials. The length of time between trials did not exceed 3 weeks.

\section{Study 2 Results}

Figure 2 depicts all four participants' facilitation fidelity of the ACT experiential exercises in a multiple baseline design. Figure 2 includes facilitation fidelity data from baseline, posttraining, and at the 1-month follow-up (i.e., Phase 1, Phase 3, Phase 5, and Phase 6). Participant 8 was unable to complete the first baseline assessment due to personal reasons. For the first baseline measure, Participants 5-7 demonstrated slightly variable and low to moderate fidelity scores in the first baseline measure $(M=24.47 \%, S D=18.52$, range: $6.25 \%-$ $56 \%$ ). Following the virtual, monthly follow-up sessions, the baseline scores increased ( $M=36.67 \%, S D=19.60$, range: $6.25 \%-69 \%$ ). Following the implementation of BST via telecommunication, significant level change was demonstrated $(M=97 \%, S D=4.30$, range: $75 \%-100 \%)$. The average mean shift from the two baseline measures to Phase 3 was $63.41 \%$ across participants. In Phase 3, facilitation fidelity of the untrained skill (le'go) increased but remained below the predetermined performance criterion $(M=61 \%, S D=9.56$, range: $50 \%-69 \%)$. Therefore, training was provided to all

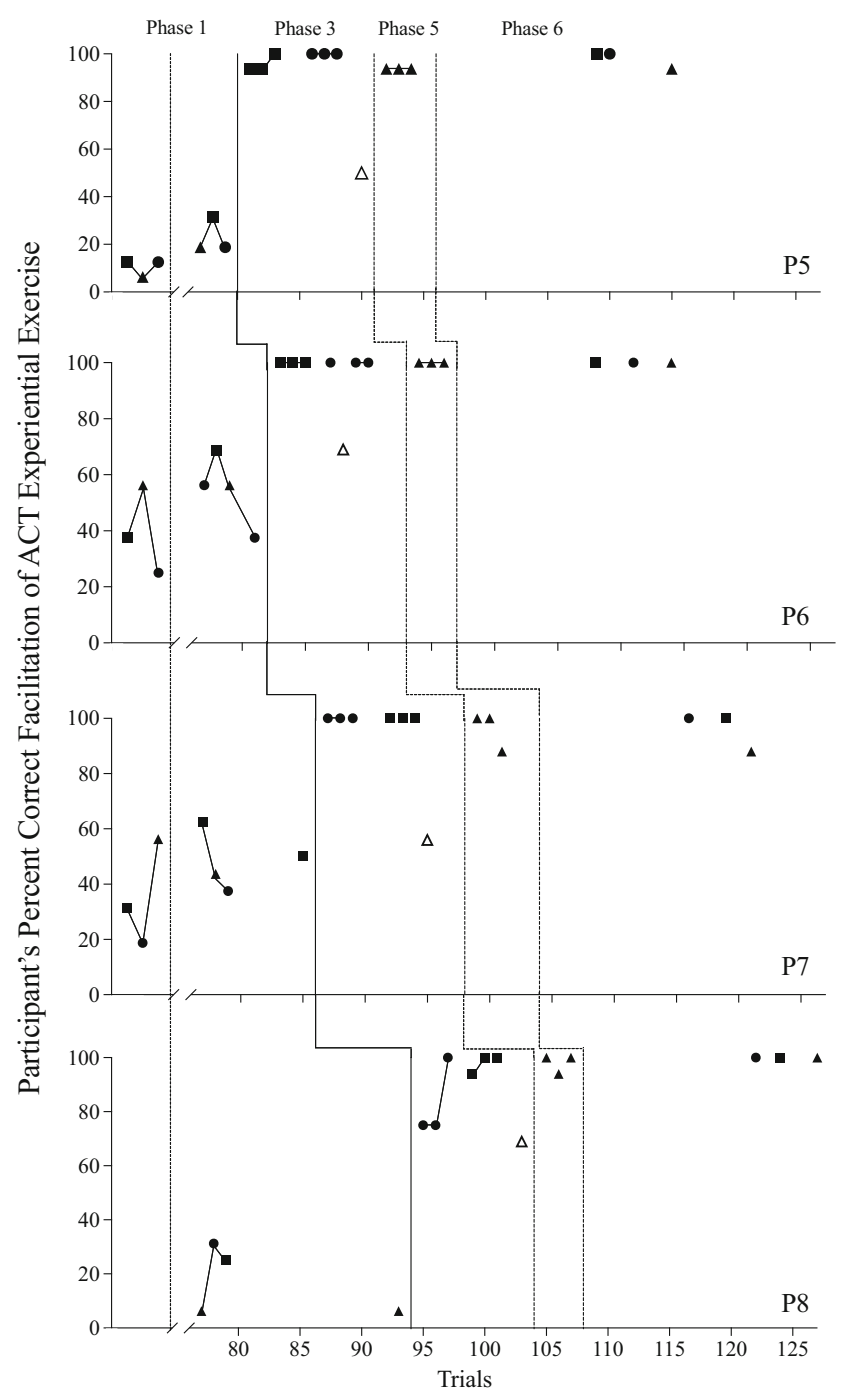

Fig. 2 Participants' Facilitation Fidelity of ACT Exercises. Note. Dotted line outlines the different baseline assessments. A trial included one attempt of facilitating an experiential exercise. The data path is broken when trials were conducted more than a week apart

participants for the untrained skill. Fidelity scores were high and stable following BST for the untrained skill $(M=97.97 \%$, $S D=3.93$, range: $87.50 \%-100 \%$ ). At the 1-month follow-up, fidelity for all participants remained high and stable $(M=$ $97.00 \%, S D=5.10$, range: $88 \%-100 \%)$.

Results of facilitators' performance during training (Phase 2 and Phase 4) of the intervention are displayed in Table 3. Overall, the implementation of BST led to an immediate increase in facilitation fidelity, with an average mean shift of $56.57 \%$ in Phase 2 and $58.82 \%$ in Phase 4 . The average amount of time required to complete the training for the first skill (i.e., hexaflex for Participant 7 and 8, matrix for Participant 5 and 6) was approximately $1.41 \mathrm{hr}$. This time decreased to $1.33 \mathrm{hr}$ for the second skill (i.e., matrix for 
Table 3 Number of training trials required to reach the mastery criterion

Number of trials to reach mastery criterion

\begin{tabular}{llll}
\cline { 2 - 4 } & Skill 1 & Skill 2 & Skill 3 (Untrained Skill) \\
\hline Participant 5 & 5 & 2 & 6 \\
Participant 6 & 2 & 3 & 4 \\
Participant 7 & 5 & 3 & 2 \\
Participant 8 & 2 & 5 & 2 \\
\hline
\end{tabular}

Participant 7 and 8, hexaflex for Participant 5 and 6), and increased to $1.50 \mathrm{hr}$ for the third skill (i.e., le'go).

For Participant 5, the participant reached the mastery criterion in three sessions (five trials) for this skill, and therefore, no coaching was required. Likewise, for Skill 2 (hexaflex), the participant reached the mastery criterion within one session (two trials). For Skill 3 (le'go), Participant 5 reached the mastery criterion in two sessions (three trials).

For Participant 6, the mastery criterion was achieved in one session (two trials) for the first skill (matrix), two sessions for Skill 2 (three trials) and two sessions (four trials) for the le'go exercise. Therefore, coaching was not required in the BST phases (Phase 2 and Phase 4).

Participant 7 reached the mastery criterion in three sessions (five trials), therefore, coaching was not required. For Skill 2 (matrix) the mastery criterion was reached within two sessions (three trials). For Skill 3 (le'go) the participant met the mastery criterion in one session (two trials).

Participant 8 met the mastery criterion in one session (two trials) for Skill 1 (hexaflex) and Skill 3 (le'go). For Skill 2 (matrix), Participant 8 reached the mastery criterion in three sessions (five trials), and therefore coaching was not required.

Participants ranked their confidence facilitating ACT experiential exercises as moderate following completion of the manualized, group-based ACT facilitation training ( $M=$ 3.82; using the 5-point Likert scale) and the in-person, monthly follow-up sessions $(M=3.23)$. The confidence scores of participants in Study 2 were more consistent with their facilitation fidelity scores at baseline (Phase 1) compared to participants in Study 1. Confidence scores increased after receiving BST via telecommunication $(M=4.7)$, and highest at the 1-month follow-up ( $M=4.76)$.

In general, participants rated the purpose of the study ( $M=$ $5)$, training outcomes $(\mathrm{M}=4.9)$, BST $(M=4.5)$, and the telecommunication format $(M=4.9)$ as highly acceptable using the 5-point Likert scale ( 1 = "strongly disagree," $5=$ "strongly agree"). Participants also included positive feedback in the open-ended section, including Participant 6 stating, "The entire process was informative, enjoyable and allowed for learning and confidence building. I cannot thank the researcher enough."

\section{Discussion}

This research lends important information to the telecommunication and ACT facilitation literature. The addition of BST via telecommunication led to immediate increases in facilitation fidelity scores. Limited research has explored how to effectively train ACT facilitators, and no studies to our knowledge have evaluated the training of caregivers as cofacilitators. The goal of this training was not to compare the effectiveness of the inperson, manualized group-based training to BST, but rather to investigate the effectiveness of BST to train individuals with some previous ACT facilitation training (in-person manualized, group-based training; Fung et al., 2019). Due to the 6-week period between participants completion of the ACT facilitation training and this research in Study 1, we are unable to conclude the effectiveness of the in-person training. This 6-week gap between the training may have resulted in extinction of any facilitation skills gained in the in-person training. However, Study 2 participants received additional virtual training and support after receiving the same inperson manualized, group-based training as participants in Study 1 and still demonstrated similar baseline patterns to those in Study 1. In Study 2 the second baseline assessment was conducted within 2 weeks following completion of the additional virtual follow-up sessions that were part of the manualized training. Further, the replication data provide additional support for the use of BST to teach ACT facilitators. To our knowledge, this is a novel research application of BST and extends the telecommunication literature to include ACT facilitation. Results also support previous training via telecommunication (e.g., Higgins et al., 2017), which has demonstrated the platform to be effective and acceptable.

ACT is a promising intervention for caregivers of individuals with NDDs who experience high levels of stress yet have limited resources currently available. Caregivers also can serve as effective cofacilitators (Dykens et al., 2014; Lunsky et al., 2018). Training using telecommunication platforms have been demonstrated to increase access to training by reducing geographical and financial barriers (e.g., World Health 
Organization, 2010). Using telecommunication in the current study allowed for training to be provided in a cost-effective and acceptable manner. Further, by training additional ACT facilitators, we are able to increase ACT capacity across a broad geographical area.

Within the evaluation, the untrained skill was included to add a layer of experimental control to the multiple baseline design, and it also allowed the researchers to assess whether generalization across ACT activities occurred. Although minimal data were collected, there is preliminary support that generalization may have occurred for Participant 4, 5, and 8 although more data is needed. For Participants 2, 4, 5, and 8 their fidelity facilitating the untrained skill improved marginally without explicit training, however, Participants 1, 3, 6, and 7 demonstrated minimal change in performance from baseline. The addition of the untrained skill was beneficial to include when exploring how to train additional ACT skills. For example, if generalization across behaviors occurred, less training would be required in the future. Based on the results of this study, it is likely that some individualized training for all experiential exercises will be required, however the time required to train the skills may decrease. Perhaps additional strategies (e.g., general case analysis; Sprague \& Horner, 1984) could be incorporated in future training to promote generalization across skills. Future research should consider probing additional untrained skills while implementing multiple exemplar training to assess whether generalization is more likely to occur for exemplars of the same point of the hexaflex. That is, if the facilitator has already received training for an exercise focusing on a specific core process (e.g., defusion) are they more likely to demonstrate generalization of that process even if that skill did not receive BST?

Maintenance of ACT facilitation fidelity and confidence was assessed 1-month following the posttraining probes. Fidelity was above $80 \%$ for all participants at follow-up, and therefore no booster sessions were provided. For Participants 1 and 3, performance increased at follow-up, with $100 \%$ fidelity on facilitation of all three experiential exercises. For Participants 2 and 4, performance for one experiential exercise (i.e., hexaflex) remained at $100 \%$, and for the others, followup fidelity scores were just below $100 \%$. For Participants 5 through 8 , follow-up scores were equivalent to their posttraining fidelity scores. It is interesting that participants with a slower rate of skill acquisition facilitated almost all experiential exercises with $100 \%$ fidelity at follow-up, and those that met the performance criterion in fewer training trials facilitated the experiential activities with slightly lower fidelity (range: $88 \%-100 \%$ ). These results may suggest that a higher performance criterion (e.g., three trials at $100 \%$ rather than two) would be beneficial to improve the maintenance of these skills. By increasing the performance criterion, participants that master the skill in a limited number of trials will still have additional practice, although it would decrease the efficiency of the training.

In baseline, Participant 1 did not facilitate the correct experiential activity for two probe assessments despite being provided with the manual, activity title, and page number of the experiential exercise in the manual (i.e., Participant 1 facilitated "leaves on a stream" rather than describing the hexaflex, and "bulls-eye" rather than the matrix). This, along with the overall low baseline scores may indicate that adequate motivating operations were lacking in this phase (Laraway et al., 2003; Michael, 1993), or the conditions did not emulate a natural training condition (e.g., the researcher role-playing and asking questions may not have been adequate discriminative stimuli for facilitating accurately; Cooper et al., 2020). It is interesting that for Study 1, participants indicated high confidence scores in baseline following the in-person manualized, group-based ACT facilitation training, which was inconsistent with their low fidelity scores in baseline. Although slightly lower than the confidence scores reported by Study 1 participants, Study 2 participants indicated moderate to high confidence following the in-person manualized, group-based ACT facilitation training. It is interesting that participants' confidence ratings decreased following the additional virtual, monthly follow-up sessions that were part of the manualized training. Perhaps as participants further explored and facilitated these activities throughout the baseline assessment for this research and the virtual, monthly follow-up sessions, participants contacted the complexity of facilitating ACT, which negatively affected their confidence. Therefore, the increases in confidence for participants in Study 1 and Study 2 following training were relatively minimal given that ceiling effects likely affected these results. These results support the use of objective measures (e.g., measuring direct, observable behaviors) versus subjective measures (e.g., self-report) to ensure corresponding behavior change after conducting any form of training.

The results of this research provide preliminary support that BST via telecommunication is an effective strategy to train ACT facilitators to deliver three experiential exercises. However, with the range of ACT experiential exercises included in the manual (Fung et al., 2019), there are some exercises that do not lend as well 
to the telecommunication platform as others. For example, some exercises involve the physical participation of group workshop attendees that would involve modifications in order to be appropriate for the online format. Therefore, the telecommunication format reduced some barriers and resulted in some additional minor barriers. Some participants required support to set-up and initially connect via Lifesize ${ }^{\mathrm{TM}}$, however, all issues were able to be resolved through email or by phone. Only once did we have to change to a different online platform when the Lifesize ${ }^{\mathrm{TM}}$ software was not working. Further, weak wi-fi connectivity did arise with some participants, but it did not impede the training process.

This research was not without limitations. Generalization of the participants' ACT facilitation fidelity was not assessed in a workshop format or with a novel recipient. All training occurred individually with the trainer role-playing an ACT workshop recipient. During a workshop as per Fung et al. (2019), facilitators would be leading experiential exercises in-person and to a group of individuals. Unfortunately, collecting facilitation fidelity during an ACT workshop was not feasible given that the participants have experienced delays in conducting in-person ACT workshops due to the COVID-19 pandemic. Further, in-person data collection during a group ACT-workshop may not be feasible given location (all facilitators residing a distance from the trainer) and may also affect the comfortability of the workshop for the workshop recipients. However, given the increase in confidence and acceptability of the intervention, the training may still be relevant in that it was perceived as valuable by participants. The training was also conducted with individuals that had already received a manualized, group-based ACT facilitation training. Therefore, we are unsure if this training would be effective for individuals without previous ACT training. Further, the maintenance of facilitation skills was assessed at 1-month. Given that facilitators are likely to require maintaining these skills longer than 1 month, it would have been more naturalistic to collect a longerterm follow-up, such as at 6 months. In addition, the dependent measure was collected by the trainer. Despite this being more efficient, there is the potential for experimenter bias to affect the results. To combat this, IOA was collected on all measures to ensure the trainer was coding in an accurate and reliable manner.

Future research should examine the use of BST via telecommunication to teach additional ACT experiential exercises, such as those of increased complexity or less appropriate for telecommunication formats. Further, it would be helpful to examine if this training is effective for individuals that have not received a manualized, group-based ACT facilitation training. Although the training was not demonstrated to be effective in increasing the participants' fidelity in the baseline assessment phase, perhaps the training improved the participants' knowledge on the ACT principles and experiential exercises. In addition, it would be helpful to compare BST versus other training methods (e.g., self-guided practice or group practice with feedback delivered by peers) while controlling for the amount of time spent on the material. Exploring the provision of BST via telecommunication to a group that had not received the manualized, group-based ACT facilitation training would identify whether this training was needed or helpful for participants' acquisition of a basic understanding of ACT. Therefore, by implementing BST via telecommunication with those that had not received the training, we could explore if there is a need for the manualized, group-based ACT facilitation training or if the current training could be modified to accommodate individuals with no previous ACT facilitation training. Further, it is important to note that there are different levels of ACT facilitation skills, such as entry level to very experienced. The participants in this study gained entry level ACT facilitation skills, but it would be interesting to explore how to modify the training or provide additional training to support the development more complex and context-specific ACT facilitation skills. In particular, it would also be interesting to examine if the training protocol could be modified to teach in a group format online, perhaps increasing training efficiency. Although training in a group would be similar to the manualized, group-based ACT facilitation training provided, it would differ by including performance and competency-based training. Future research should also examine the generalization of these skills to a workshop format, the long-term maintenance of these skills, and context-based variation and generalization of fidelity.

\section{Appendix 1}

\section{Treatment Integrity Checklist}

Please circle the most appropriate rating for each behavior within the behavior chain by referring to the operational definitions.

* Note that the wording does not have to be verbatim as long as the main concepts are captured. 


\begin{tabular}{|c|c|c|c|c|}
\hline $\begin{array}{l}\text { Facilitation } \\
\text { Component }\end{array}$ & Competency & Operational Definition & Rating & Weighting \\
\hline \multirow{5}{*}{$\begin{array}{l}\text { Explain relevant } \\
\text { processes (based } \\
\text { on relevant } \\
\text { concepts list) }\end{array}$} & \multirow{5}{*}{ In development } & $\begin{array}{l}\text { The facilitator did not explain the } \\
\text { relevant concepts }(0 \%-24 \%) \text {. }\end{array}$ & 0 & \\
\hline & & $\begin{array}{l}\text { The facilitator provided a portion }(25 \%- \\
49 \%) \text { of the relevant concepts. }\end{array}$ & 1 & \\
\hline & & $\begin{array}{l}\text { The facilitator provided a portion }(50 \%- \\
74 \%) \text { of the relevant concepts. }\end{array}$ & 2 & \\
\hline & & $\begin{array}{l}\text { The facilitator provided a portion }(75 \%- \\
99 \%) \text { of the relevant concepts. }\end{array}$ & 3 & \\
\hline & & $\begin{array}{l}\text { The facilitator provided an accurate } \\
\text { explanation of the relevant concepts } \\
(100 \%) \text {. }\end{array}$ & 4 & 14 \\
\hline \multirow{5}{*}{$\begin{array}{l}\text { Facilitate activity } \\
\text { (based on activity } \\
\text { checklist; A1, A2, } \\
\text { and A3) }\end{array}$} & \multirow{4}{*}{ In development } & $\begin{array}{l}\text { The facilitator did not lead an activity } \\
(0 \%-24 \%) \text {. }\end{array}$ & 0 & \\
\hline & & $\begin{array}{l}\text { The facilitator led the activity including } \\
25 \%-49 \% \text { of steps on activity } \\
\text { checklist. }\end{array}$ & 1 & \\
\hline & & $\begin{array}{l}\text { The facilitator led the activity including } \\
50 \%-74 \% \text { of steps on activity } \\
\text { checklist. }\end{array}$ & 2 & \\
\hline & & $\begin{array}{l}\text { The facilitator led the activity including } \\
75 \%-99 \% \text { of steps on activity } \\
\text { checklist. }\end{array}$ & 3 & \\
\hline & Mastered & $\begin{array}{l}\text { The facilitator led the activity including } \\
100 \% \text { of steps on activity checklist. }\end{array}$ & 4 & 14 \\
\hline \multirow{7}{*}{$\begin{array}{l}\text { Debriefed } \\
\text { (following debrief } \\
\text { / discussion } \\
\text { guide) }\end{array}$} & \multirow[t]{5}{*}{ In development } & $\begin{array}{l}\text { The facilitator did not debrief after the } \\
\text { activity following the debrief / } \\
\text { discussion guide }(0 \%-24 \%) \text {. }\end{array}$ & 0 & \multirow[b]{5}{*}{$/ 4$} \\
\hline & & $\begin{array}{l}\text { The facilitator included } 25 \%-44 \% \text { of the } \\
\text { debrief / discussion guide. }\end{array}$ & 1 & \\
\hline & & $\begin{array}{l}\text { The facilitator included } 50 \%-74 \% \text { of the } \\
\text { debrief / discussion guide. }\end{array}$ & 2 & \\
\hline & & $\begin{array}{l}\text { The facilitator included } 75 \%-99 \% \text { of the } \\
\text { debrief / discussion guide. }\end{array}$ & 3 & \\
\hline & & The facilitator included $100 \%$ of the & 4 & \\
\hline & \multirow[b]{2}{*}{ Mastered } & debrief / discussion guide. & & \\
\hline & & & & \\
\hline \multirow{7}{*}{$\begin{array}{l}\text { Answered } \\
\text { questions on } \\
\text { concept }\end{array}$} & \multirow[t]{7}{*}{ In development } & $\begin{array}{l}\text { The facilitator did not provide an } \\
\text { opportunity to ask questions on the } \\
\text { scenario. }\end{array}$ & 0 & \\
\hline & & $\begin{array}{l}\text { The facilitator incorrectly answered } \\
\text { questions on the scenario. }\end{array}$ & 1 & \\
\hline & & $\begin{array}{l}\text { The facilitator answered questions on } \\
\text { the scenario using language inconsistent } \\
\text { with ACT terminology and principles. }\end{array}$ & 2 & \\
\hline & & $\begin{array}{l}\text { The facilitator answered questions using } \\
\text { little ACT terminology }\end{array}$ & 3 & \\
\hline & & $\begin{array}{l}\text { The facilitator answered questions using } \\
\text { ACT terminology. }\end{array}$ & \multirow{3}{*}{4} & \\
\hline & & & & \\
\hline & & & & $/ 4$ \\
\hline
\end{tabular}




\section{Relevant Processes}

\section{Matrix}

Values (Know What Matters)

- Desired qualities of ongoing action, describing how we want to behave on an ongoing basis.

Committed Action (Do What it Takes)

- Taking larger and larger patterns of effective action, guided by values.

\section{Hexaflex}

Psychological Flexible Processes:

Contacting the Present Moment (Be Here Now)

- Being psychologically present: consciously connecting with and engaging in whatever is happening in the moment.

\section{Defusion (Watch Your Thinking)}

- Learning to "step back" and separate or detach from our thoughts, images, and memories.

\section{Acceptance (Open Up)}

- Opening up and making room for painful feelings, sensations, urges, and emotions.

\section{Self-as-Context (Pure Awareness)}

- Being aware of having the thinking-self and the observing-self and being aware of whatever we are thinking, feeling, sensing, and doing in any moment.

\section{Values (Know What Matters)}

- Desired qualities of ongoing action, describing how we want to behave on an ongoing basis.

Committed Action (Do What it Takes)
- Taking larger and larger patterns of effective action, guided by values.

Psychological Inflexible Processes:

Dominance of the conceptualized past and feared future

- Being stuck in our thoughts of the past or concerns about the future.

Cognitive fusion

- Treating our thoughts as reality.

Experiential avoidance

- The attempt to avoid unwanted thoughts, feelings, bodily sensations, or memories even though it may be costly to our well-being or be ineffective or unnecessary.

Attachment to the conceptualized self (or self-as-content)

- Getting stuck to a fused identity that is based on evaluations, concepts, and stories we have about who we are.

Lack of values clarity

- Not being in touch with our chosen values or what really matters to us.

Inaction, impulsivity, or avoidance

- Patterns of behavior that reinforce our psychological struggles and prevent us from engaging in present moment awareness and valued living.

\section{Le'go}

\section{Self-as-Context (Pure Awareness)}

- Being aware of having the thinking-self and the observing-self and being aware of whatever we are thinking, feeling, sensing, and doing in any moment. 


\section{Activity Checklists}

\section{A1: Matrix}

Y/N/ Step Description

NA

1. Introduce Activity

"In this activity, we will focus again on the perspective of psychological flexibility — doing more of the things that are important to you, your child and your family. As you saw in the previous activity, the phrase Psychological Flexibility is in the center of the hexaflex. Psychological flexibility involves all six core processes of the ACT model."

2. Have materials ready and organized (paper and marker)

3. Explain the y-axis (mental vs. outer world experiencing)

4. Explain the x-axis (towards vs. away)

5. Explain the first quadrant and write responses

a. Who and what matters most (values)

"Now, let's discuss the upper right quadrant, Values - this is who and what matters most to us. So, think about this question: who and what matters most to you?"

6. Explain the second quadrant and write responses

a. Toward behaviors (committed actions)

"When you consider who and what matters most to you, what are some of the actions I and others would see you doing in the service of your values? I will write these actions in the lower right-hand quadrant under 'Committed actions.' These actions are experienced in the "outer world"; in other words, they are not just inner thoughts, but are actions that you and others would see and experience."

7. Explain the third quadrant and provide 1 minute to write responses

a. Unwanted internal thoughts

"When we are moving toward who and what matters (the upper right quadrant—Values), thoughts and feelings sometimes show up inside us that we'd rather get away from."

8. Explain the fourth quadrant and write responses

a. Away behaviors

"Now, when these internal barriers (negative thoughts or feelings) show up, what are some avoidant behaviors that you may do to make these feelings go away or lessen them? For example, when I feel, say, fearful or fatigued, I may do something like yell, avoid, watch TV, or ignore the kids. These are things that you do, behaviors that others can see, so I'll write them below (in the Outer world) under 'Avoidant behaviors' - my actions to avoid negative experiences.

"So, what are some things you do to move away?"

9. Ask participants to notice if these away behaviors are helpful (short term/long term).

10. "Me noticing" component of tool 


\section{A2: Hexaflex}

Y/N/ Step Description
NA
1. Demonstrate hand gesture for defusion
2. Have participants engage in hand gesture for defusion
3. Demonstrate hand gesture for acceptance
4. Have participants engage in hand gesture for acceptance
5. Demonstrate hand gesture for contact with present moment
6. Have participants engage in hand gesture for present moment
7. Demonstrate hand gesture for contact with self-as-context
8. Have participants engage in hand gesture for self-as-context
9. Demonstrate hand gesture for values
10. Have participants engage in hand gesture for values
11. Demonstrate hand gesture for committed actions
12. Have participants engage in hand gesture for committed
actions

\section{A3: Le'go}

Y/N/ Step Description

NA

1. Introduce Activity

"As we have explored, our thoughts often are not what they seem. This may even apply to thoughts about ourselves.

“This activity is called the Le' go (or Let-go) exercise. It will help us explore our sense of self- that is, our sense of who we are."

2. Distribute Materials

Ensure participant has materials (plate, Lego pieces) in front of them and inform them write down your name on the plate so you can identify which plate is theirs.

3. Have participants become quiet and mindful to the present.

Say "Please put down your plate. If you are willing, close your eyes, or alternatively fix your gaze on a point in front of you. We will just spend a few moments to become aware of the present and our breath."

4. Direct them to deeply recall a memory from childhood/teenage years/recent.

Recent "Now let's think back to something that happened to you this summer. It may be a positive event or a negative event - whatever comes to your mind. Recall the event as clearly as you can. Notice what you were seeing, hearing, doing, feeling or thinking at the time. Notice where you were and whom you were with."

Teen/Child "Looking at the pieces in front of you, now recall another event, this time from your teenage/childhood years. Notice everything that you were seeing, hearing, doing, thinking and feeling back then. Notice that your role then may have been quite different from your role now. Notice that your body may have been quite different then, too. Maybe every single cell in your body was different back then. Yet notice too that the 'you' that was there back then is the (continued)

$\mathrm{Y} / \mathrm{N} /$

NA

(continued)

Step

Descri-

ption

same 'you' that is here now recalling all this, looking at these Lego pieces."

5. Ask them to note that there was a "self" that observed everything that was happening at the time - the same "self" that is here now recalling the memory.

"Notice that you were there experiencing all these things, and notice that this is the same 'you' that is here right now, recalling all of this. Note that 'you' have been 'you' all this time."

6. "Let us return for a few moments to our breath and to just being here. Whenever you are ready, you may open your eyes."

Ask participants to recreate the memory with Lego pieces

"Now, being fully present, see if you can use the construction blocks to recreate the event you just recalled from last summer or represent the event in some way."

8. Provide appropriate amount of time to build (i.e., 2-5 min)

9. Conclude exercise

"Please stop building if you have not already finished. Whatever stage you are at, take a moment just to observe the memory of that event from , and notice that the same " you' is here now, observing all this as an adult."

Take apart the figure and observe how you feel while doing so. (return to step 4 and repeat for teenage and childhood years)

"Now let's let all these memories go ... and return together to this room in the present moment."

10. Lead discussion

"Would anyone like to share their experience of this exercise?"

\section{Debrief / Discussion Guides}

\section{Matrix}

Highlight for participants that the purpose of using the matrix is to increase psychological flexibility.

- Flexibility results from realizing that we have the choice either to move toward who and what is important to us (value-based committed action), or to more consciously continue attempts to manage our internal experiences such as our thoughts and feelings (even though we see this strategy doesn't work well).

- If we choose this second strategy, we at least can do so without judgment and with more consciousness. 


\section{Hexaflex}

- All of the processes are interconnected

- Together they create the hexaflex

- Not one process is more important than others

- Leads to psychological flexibility

Le'go

- "observer-self" (the experience of the same "I" who is aware and observing) is continuously present throughout our lives, amidst all the changes.

- Resilience and the persistence of "self" through the challenges of life.

- Being constricted by our own self-stories - we can easily confuse our "selves" with ideas and concepts about ourselves, like our self-descriptions, stories or social roles, and feel "bounded" by these things.

- Feeling loss of self when things change

- "Take-home" metaphor: self-as-context (the container).

\section{Appendix 2}

\section{Procedural Integrity Checklist for Training Sessions}

\section{Instructions}

- Provide the participant with instructions on how to facilitate an ACT activity or explain an ACT concept accurately by:

Ensuring that the participant is attending (i.e., attention directed towards researcher, not distracted by phone, other).

Providing instructions outlining the relevant ACT activity or concept using clear and concise language.

Providing a brief rationale for why the relevant ACT activity or concept is important clearly and succinctly.

\section{Video Modeling}

- Provide the participant with a demonstration on how to teach the relevant ACT activity or concept by:

A. Ensuring that the participant is attending (e.g., attention directed towards researcher, not distracted by phone, other).

B. Providing an instruction that indicates to the participant they will be imitating this skill.
C. Providing a video model of facilitating the relevant component of ACT.

\section{Rehearsal}

- Provide the participant with an opportunity to practice teaching the ACT concept/activity.

\section{Feedback \& Coaching}

- Provide feedback to the participant on their rehearsal of the ACT concept/activity by:

Providing immediate feedback (i.e., within 3-5 s) following the practice opportunity.

Providing descriptive social praise (e.g., "Nice job explaining acceptance!")

OR

Providing corrective feedback (e.g., "Next time, maybe you want to consider trying to. ...")

Providing an opportunity for the participant to rehearse again if mastery criterion has not been met.

Supplementary Information The online version contains supplementary material available at https://doi.org/10.1007/s40617-021-00628-x.

Funding This research was supported by a grant from the Social Sciences and Humanities Research Council of Canada.

\section{Declarations}

Conflicts of Interest The authors declare that there are no conflicts of interest relevant to the content of this article.

Ethics Approval Ethics approval was received from Brock University's Research Ethics Board. The procedures implemented in this study abide to the tenets of the Declaration of Helsinki. Informed consent was obtained from all participants included in the study.

\section{References}

Baer, D. M., Wolf, M. M., \& Risley, T. R. (1968). Some current dimensions of applied behavior analysis. Journal of Applied Behavior Analysis, 1(1), 91-97. https://doi.org/10.1901/jaba.1987.20-313.

Barkaia, A., Stokes, T. F., \& Mikiashvili, T. (2017). Intercontinental telehealth coaching of therapists to improve verbalizations by children with autism. Journal of Applied Behavior Analysis, 50(3), 582589. https://doi.org/10.1002/jaba.391.

Barnes-Holmes, Y., Barnes-Holmes, D., McHugh, L., \& Hayes, S. C. (2004). Relational frame theory: Some implications for understanding and treating human psychopathology. International Journal of 
Psychology \& Psychological Therapy, 4, 355-375 http://mural. maynoothuniversity.ie/402/1/Psyc21.pdf. Retrieved January 2019.

Barnes-Holmes, Y., Foody, M., Barnes-Holmes, D., \& McHugh, L. (2013). Advances in research on deictic relations and perspective taking. In S. Dymond \& B. Roche (Eds.), Advances in relational frame theory: Research and application (pp. 127-148). Context Press/New Harbinger.

Behavior Analyst Certification Board. (2017). BCBA/BCaBA task list (5th ed.). Author.

Blackledge, J. T., \& Hayes, S. C. (2006). Using Acceptance and commitment training in the support of parents of children diagnosed with autism. Child \& Family Behavior Therapy, 28(1), 1-18. https://doi. org/10.1300/j019v28n01_01.

Brown, F. L., Whittingham, K., Boyd, R. N., McKinlay, L., \& Sofronoff, K. (2015). Does Stepping Stones Triple P plus Acceptance and Commitment Therapy improve parent, couple, and family adjustment following paediatric acquired brain injury? A randomised controlled trial. Behaviour Research \& Therapy, 73, 58-66. https://doi. org/10.1016/j.brat.2015.07.001.

Cooper, J., Heron, T., \& Heward, W. (2020). Applied behavior analysis (3rd ed.). Pearson.

Davis, S., Thomson, K., \& Connolly, M. (2019). A component analysis of behavioral skills training with volunteers teaching motor skills to individuals with developmental disabilities. Behavioral Interventions, 34(4), 431-450. https://doi.org/10.1002/bin.1688.

Derksen, F., Bensing, J., \& Lagro-Janssen, A. (2013). Effectiveness of empathy in general practice: a systematic review. British Journal of General Practice, 63(606), 76-84. https://doi.org/10.3399/ bjgp13X660814.

Dykens, E. M., Fisher, M. H., Taylor, J. L., Lambert, W., \& Miodrag, N. (2014). Reducing distress in mothers of children with autism and other disabilities: a randomized trial. Pediatrics, 134(2), 454-463. https://doi.org/10.1542/peds.2013-3164.

Dymond, S., \& Barnes, D. (1997). Behavior-analytic approaches to selfawareness. The Psychological Record, 47(2), 181-200. https://doi. org/10.1007/BF03395219.

Enoch, M. R., \& Nicholson, S. L. (2020). Acceptance and commitment therapy and relational frame theory in the field of applied behavior analysis: The acceptability and perspective of the practicing BCBA. Behavior Analysis in Practice, 13(3), 609-617. https://doi.org/10. 1007/s40617-020-00416-Z

Estes, A., Munson, J., Dawson, G., Koehler, E., Zhou, X., \& Abbott, R. (2009). Parenting stress and psychological functioning among mothers of preschool children with autism and developmental delay. Autism, 13(4), 375-387. https://doi.org/10.1177/ 1362361309105658.

Fletcher, L., \& Hayes, S. C. (2005). Relational frame theory, acceptance and commitment therapy, and a functional analytic definition of mindfulness. Journal of Rational-Emotive \& Cognitive-Behavior Therapy, 23(4), 315-336. https://doi.org/10.1007/s10942-005$0017-7$.

Foody, M., Barnes-Holmes, Y., Barnes-Holmes, D., \& Luciano, C. (2013). An empirical investigation of hierarchical versus distinction relations in a self-based ACT exercise. International Journal of Psychology \& Psychological Therapy, 13(3), 373-388.

Fryling, M. J., Wallace, M. D., \& Yassine, J. N. (2012). Impact of treatment integrity on intervention effectiveness. Journal of Applied Behavior Analysis, 45(2), 449-453. https://doi.org/10.1901/jaba. 2012.45-449.

Fung, K., Lake, J., Steel, L., Bryce, K., \& Lunsky, Y. (2018). ACT processes in group intervention for mothers of children with autism spectrum disorder. Journal of Autism \& Developmental Disorders, 48(8), 2740-2747. https://doi.org/10.1007/s10803-018-3525-x.

Fung, K., Lunsky, Y., Steel, L., Lake, J., \& Bryce, K. (2019). Acceptance and commitment training (ACT) manual for parents with children with disabilities. CAMH Publications.
Gloster, A. T., Walder, N., Levin, M., Twohig, M., \& Karekla, M. (2020). The empirical status of acceptance and commitment Therapy: A review of meta-analyses. Journal of Contextual Behavioral Science, 18, 181-192. https://doi.org/10.1016/j.jcbs.2020.09.009.

Gould, E. R., Tarbox, J., \& Coyne, L. (2018). Evaluating the effects of acceptance and commitment training on the overt behavior of parents of children with autism. Journal of Contextual Behavioral Science, 7, 81-88. https://doi.org/10.1016/j.jcbs.2017.06.003.

Gross, A. C., \& Fox, E. J. (2009). Relational frame theory: An overview of the controversy. Analysis of Verbal Behavior, 25(1), 87-98. https://doi.org/10.1007/bf03393073.

Gunby, K. V., \& Rapp, J. T. (2014). The use of behavioral skills training and in situ feedback to protect children with autism from abduction lures. Journal of Applied Behavior Analysis, 47(4), 856-860. https:// doi.org/10.1002/jaba.173.

Hahs, A. D., Dixon, M. R., \& Paliliunas, D. (2018). Randomized controlled trial of a brief acceptance and commitment training for parents of individuals diagnosed with autism spectrum disorders. Journal of Contextual Behavioral Science, 12, 154-159. https:// doi.org/10.1016/j.jcbs.2018.03.002.

Harris, R. (2009). ACT made simple: An easy-to-read primer on acceptance and commitment therapy. New Harbinger.

Hassan, M., Thomson, K. M., Khan, M., Burnham Riosa, P., \& Weiss, J. A. (2017). Behavioral skills training for graduate students providing cognitive behavior therapy to children with autism spectrum disorder. Behavior Analysis: Research \& Practice, 17(2), 155. https://doi. org/10.1037/bar0000078155.

Hassan, M., Simpson, A., Danaher, K., Haesen, J., Makela, T., \& Thomson, K. (2018). An evaluation of behavioral skills training for teaching caregivers how to support social skill development in their child with autism spectrum disorder. Journal of Autism \& Developmental Disorders, 48(6), 1957-1970. https://doi.org/10. 1007/s10803-017-3455-z.

Hayes, S. C. (2004). Acceptance and commitment therapy, relational frame theory, and the third wave of behavioral and cognitive therapies. Behavior Therapy, 35(4), 639-665. https://doi.org/10.1016/j. beth.2016.11.006.

Hayes, S. C., Wilson, K. G., Gifford, E. V., Follette, V. M., \& Strosahl, K. (1996). Experiential avoidance and behavioral disorders: A functional dimensional approach to diagnosis and treatment. Journal of Consulting \& Clinical Psychology, 64(6), 1152. https://doi.org/10. 1037/0022-006X.64.6.1152.

Hayes, S. C., Strosahl, K. D., \& Wilson, K. G. (1999). Acceptance and commitment therapy: An experiential approach to behavior change. Guilford Press.

Hayes, S. C., Luoma, J. B., Bond, F. W., Masuda, A., \& Lillis, J. (2006). Acceptance and commitment therapy: Model, processes and outcomes. Behaviour Research \& Therapy, 44, 1-25. https://doi.org/ 10.1016/j.brat.2005.06.006.

Hayes, S. C., Levin, M. E., Plumb-Vilardaga, J., Villatte, J. L., \& Pistorello, J. (2013). Acceptance and commitment therapy and contextual behavioral science: Examining the progress of a distinctive model of behavioral and cognitive therapy. Behavior Therapy, 44(2), 180-198. https://doi.org/10.1016/j.beth.2009.08.002.

Healy, O., Barnes-Holmes, D., \& Smeets, P. M. (2000). Derived relational responding as generalized operant behavior. Journal of the Experimental Analysis of Behavior, 74(2), 207. https://doi.org/10. 1901/jeab.2000.74-207.

Higgins, W. J., Luczynski, K. C., Carroll, R. A., Fisher, W. W., \& Mudford, O. C. (2017). Evaluation of a telehealth training package to remotely train staff to conduct a preference assessment. Journal of Applied Behavior Analysis, 50(2), 239-251. https://doi.org/10.1002/ jaba.370.

Hoffmann, A. N., Contreras, B. P., Clay, C. J., \& Twohig, M. P. (2016). Acceptance and commitment therapy for individuals with disabilities: A behavior analytic strategy for addressing private events in 
challenging behavior. Behavior Analysis in Practice, 9(1), 14-24. https://doi.org/10.1007/s40617-016-0105-4.

Hogan, A., Knez, N., \& Kahng, S. (2015). Evaluating the use of behavioral skills training to improve school staffs' implementation of behavior intervention plans. Journal of Behavioral Education, 24(2), 242-254. https://doi.org/10.1007/s10864-014-9213-9.

Hoy, A. W. (2000, April). Changes in teacher efficacy during the early years of teaching. Paper presented at the American Educational Research Association's Annual Meeting, New Orleans, LA.http:// stelar.edc.org/sites/stelar.edc.org/files/Hoy\%20\%282000\%29.pdf. Accessed September 2019.

Joekar, S., Farid, A. A., Birashk, B., Gharraee, B., \& Mohammadian, M. (2016). Effectiveness of acceptance and commitment therapy in the support of parents of children with high-functioning autism. International Journal of Humanities \& Cultural Studies, 2, 27632772.

Keeley, M. L., Geffken, G. R., Ricketts, E., McNamara, J. P., \& Storch, E. A. (2011). The therapeutic alliance in the cognitive behavioral treatment of pediatric obsessive-compulsive disorder. Journal of Anxiety Disorders, 25(7), 855-863. https://doi.org/10.1016/j. janxdis.2011.03.017.

Kirby, J. N., Tellegen, C. L., \& Steindl, S. R. (2017). A meta-analysis of compassion-based interventions: Current state of knowledge and future directions. Behavior Therapy, 48(6), 778-792. https://doi. org/10.1016/j.beth.2017.06.003.

Laraway, S., Snycerski, S., Michael, J., \& Poling, A. (2003). Motivating operations and terms to describe them: Some further refinements. Journal of Applied Behavior Analysis, 36(3), 407-414. https://doi. org/10.1901/jaba.2003.36-407.

Little, A., Tarbox, J., \& Alzaabi, K. (2020). Using acceptance and commitment training to enhance the effectiveness of behavioral skills training. Journal of Contextual Behavioral Science, 16, 9-16. https://doi.org/10.1016/j.jcbs.2020.02.002.

Losada, A., Márquez-González, M., Romero-Moreno, R., Mausbach, B. T., López, J., Fernández-Fernández, V., \& Nogales-González, C. (2015). Cognitive-behavioral therapy (CBT) versus acceptance and commitment therapy (ACT) for dementia family caregivers with significant depressive symptoms: Results of a randomized clinical trial. Journal of Consulting \& Clinical Psychology, 83(4), 760. https://doi.org/10.1037/ccp0000028760.

Lunsky, Y., Fung, K., Lake, J., Steel, L., \& Bryce, K. (2018). Evaluation of acceptance and commitment therapy (ACT) for mothers of children and youth with autism spectrum disorder. Mindfulness, 9(4), 1110-1116. https://doi.org/10.1007/s12671-017-0846-3.

Magnacca, C., Thomson, K., \& Marcinkiewicz, A. (2021). Acceptance and commitment therapy for caregivers of children with neurodevelopmental disabilities: A systematic review. Current Developmental Disorders Reports, 8, 152-160. https://doi.org/10. 1007/s40474-021-00228-y.

McEnteggart, C. (2018). A brief tutorial on acceptance and commitment therapy as seen through the lens of derived stimulus relations. Perspectives on Behavior Science, 41, 215. https://doi.org/10. 1007/s40614-018-0149-6.

Michael, J. (1993). Establishing operations. The Behavior Analyst, 16(2), 191-206. https://doi.org/10.1007/BF03392623.

Miles, N. I., \& Wilder, D. A. (2009). The effects of behavioral skills training on caregiver implementation of guided compliance. Journal of Applied Behavior Analysis, 42(2), 405-410. https://doi. org/10.1901/jaba.2009.42-405.

Miodrag, N., \& Hodapp, R. M. (2010). Chronic stress and health among parents of children with intellectual and developmental disabilities. Current Opinion in Psychiatry, 23(3), 407-411. https://doi.org/10. 1111/jir.12135.

Nigro-Bruzzi, D., \& Sturmey, P. (2010). The effects of behavioral skills training on mand training by staff and unprompted vocal mands by children. Journal of Applied Behavior Analysis, 43(4), 757-761. https://doi.org/10.1901/jaba.2010.43-757.

Parsons, M., Rollyson, J., \& Reid, D. (2012). Evidence-based staff training: A guide for practitioners. Behavior Analysis in Practice, 5(2), 2-11. https://doi.org/10.1007/BF03391819.

Plumb, J. C., \& Vilardaga, R. (2010). Assessing treatment integrity in acceptance and commitment therapy: Strategies and suggestions. International Journal of Behavioral Consultation \& Therapy, 6(3), 263-295. https://doi.org/10.1037/h0100912.

Poddar, S., Sinha, V. K., \& Urbi, M. (2015). Acceptance and commitment therapy on parents of children and adolescents with autism spectrum disorders. International Journal of Educational \& Psychological Researches, 1(3), 221. https://doi.org/10.4103/23952296.158331.

Reimers, T. M., Wacker, D. P., \& Cooper, L. J. (1991). Evaluation of the acceptability of treatments for children's behavioral difficulties: Ratings by parents receiving services in an outpatient clinic. Child \& Family Behavior Therapy, 13(2), 53-71. https://doi.org/10.1300/ J019v13n02 04.

Sarokoff, R. A., \& Sturmey, P. (2004). The effects of behavioral skills training on staff implementation of discrete-trial teaching. Journal of Applied Behavior Analysis, 37(4), 535-538. https://doi.org/10.1901/ jaba.2004.37-535.

Snyder, K., Lambert, J., \& Twohig, M. P. (2011). Defusion: A behavioranalytic strategy for addressing private events. Behavior Analysis in Practice, 4(2), 4-13. https://doi.org/10.1007/BF03391779.

Sprague, J. R., \& Horner, R. H. (1984). The effects of single instance, multiple instance, and general case training on generalized vending machine use by moderately and severely handicapped students. Journal of Applied Behavior Analysis, 17(2), 273-278. https://doi. org/10.1901/jaba.1984.17-273.

Suess, A. N., Wacker, D. P., Schwartz, J. E., Lustig, N., \& Detrick, J. (2016). Preliminary evidence on the use of telehealth in an outpatient behavior clinic. Journal of Applied Behavior Analysis, 49(3), 686-692. https://doi.org/10.1002/jaba.305.

Sump, L. A., Richman, D. M., Schaefer, A. M., Grubb, L. M., \& Brewer, A. T. (2018). Telehealth and in-person training outcomes for novice discrete trial training therapists. Journal of Applied Behavior Analysis, 51(3), 466-481. https://doi.org/10.1002/jaba.461.

Szabo, T. G. (2019). Acceptance and commitment training for reducing inflexible behaviors in children with autism. Journal of Contextual Behavioral Science, 12, 178. https://doi.org/10.1016/j.jcbs.2019.03. 001.

Tarbox, J., Szabo, T. G., \& Aclan, M. (2020). Acceptance and commitment training within the scope of practice of applied behavior analysis. Behavior Analysis in Practice, 1-22. https://doi.org/10.1007/ s40617-020-00466-3.

Taylor, J. L., \& Warren, Z. E. (2012). Maternal depressive symptoms following autism spectrum diagnosis. Journal of Autism \& Developmental Disorders, 42(7), 1411-1418. https://doi.org/10. 1007/s10803-011-1375-x.

Taylor, B. A., LeBlanc, L. A., \& Nosik, M. R. (2019). Compassionate care in behavior analytic treatment: Can outcomes be enhanced by attending to relationships with caregivers? Behavior Analysis in Practice, 12(3), 654-666. https://doi.org/10.1007/s40617-01800289-3.

Tomlinson, S. R., Gore, N., \& McGill, P. (2018). Training individuals to implement applied behavior analytic procedures via telehealth: A systematic review of the literature. Journal of Behavioral Education, 27(2), 172-222. https://doi.org/10.1007/s10864-0189292-0.

Twohig, M. P., Hayes, S. C., Plumb, J. C., Pruitt, L. D., Collins, A. B., Hazlett-Stevens, H., \& Woidneck, M. R. (2010). A randomized clinical trial of acceptance and commitment therapy versus progressive relaxation training for obsessive-compulsive disorder. Journal 
of Consulting \& Clinical Psychology, 78(5), 705. https://doi.org/10. 1037/a0020508.

Wacker, D. P., Lee, J. F., Padilla Dalmau, Y. C., Kopelman, T. G., Lindgren, S. D., Kuhle, J., Pelzel, K. E., \& Waldron, D. B. (2013a). Conducting functional analyses of problem behavior via telehealth. Journal of Applied Behavior Analysis, 46(1), 1-16. https://doi.org/10.1002/jaba.29.

Wacker, D. P., Lee, J. F., Padilla Dalmau, Y. C., Kopelman, T. G., Lindgren, S. D., Kuhle, J., Pelzel, K. E., Dyson, S., Schieltz, K. M., \& Waldron, D. B. (2013b). Conducting functional communication training via telehealth to reduce the problem behavior of young children with autism. Journal of Developmental \& Physical Disabilities, 25(1), 35-48. https://doi.org/10.1007/s10882-0129314-0.

Ward-Horner, J., \& Sturmey, P. (2012). Component analysis of behavior skills training in functional analysis. Behavioral Interventions, 27(2), 75-92. https://doi.org/10.1002/bin.1339.
Weiss, R., Vittinghoff, E., Fang, M. C., Cimino, J. E., Chasteen, K. A., Arnold, R. M., Auerbach, A. D., \& Anderson, W. G. (2017). Associations of physician empathy with patient anxiety and ratings of communication in hospital admission encounters. Journal of Hospital Medicine, 12(10), 805-810. https://doi.org/10.12788/jhm. 2828.

Whittingham, K., Sanders, M. R., McKinlay, L., \& Boyd, R. N. (2016). Parenting intervention combined with acceptance and commitment therapy: A trial with families of children with cerebral palsy. Journal of Pediatric Psychology, 41, 531-542. https://doi.org/10.1093/ jpepsy/jsv118.

World Health Organization. (2010). Telemedicine: Opportunities and developments in member states. https://www.who.int/goe/ publications/goe_telemedicine_2010.pdf. Accessed January 2019.

Publisher's Note Springer Nature remains neutral with regard to jurisdictional claims in published maps and institutional affiliations. 